\title{
Assessing the shape symbolism of the taste, flavour, and texture of foods and beverages
}

\author{
Charles Spence ${ }^{*}$ and Mary Kim Ngo
}

\begin{abstract}
Consumers reliably match a variety of tastes (bitterness, sweetness, and sourness), oral-somatosensory attributes (carbonation, oral texture, and mouth-feel), and flavours to abstract shapes varying in their angularity. For example, they typically match more rounded forms such as circles with sweet tastes and more angular shapes such as triangles and stars with bitter and/or carbonated foods and beverages. Here, we suggest that such shape symbolic associations could be, and in some cases already are being, incorporated into the labelling and/or packaging of food and beverage products in order to subconsciously set up specific sensory expectations in the minds of consumers. Given that consumers normally prefer those food and beverage products that meet their sensory expectations, as compared to those that give rise to a 'disconfirmation of expectation', we believe that the targeted use of such shape symbolism may provide a means for companies to gain a competitive advantage in the marketplace. Here, we review the latest research documenting a variety of examples of shape symbolism in the food and beverage sector. We also highlight a number of the explanations for such effects that have been put forward over the years. Finally, we summarise the latest evidence demonstrating that the shapes a consumer sees on the label and even the shape of the packaging in which the product is served can all impact on a consumer's sensory-discriminative and hedonic responses to food and beverage products.
\end{abstract}

Keywords: Shape symbolism, Taste, Flavour, Oral somatosensation, Food and beverage packaging, Sensory expectations

\section{Introduction}

Looking through the annals of marketing history, one finds occasional mention of the existence of a variety of cross-modal correspondences between abstract shapes and basic tastes. Generally speaking, cross-modal correspondences can be defined as a tendency for an individual to match (or associate) a feature, or attribute, in one sensory modality with a sensory feature, or attribute, in another sensory modality, no matter whether physically present or merely imagined [1,2]. So, for example, back in 1971, Ernst Dichter [3] reported that consumers typically matched more rounded shapes (for example, circles) with foods and beverages having a prominent sweet taste, while matching bitter-tasting foodstuffs with more angular shapes (such as stars and triangles) instead. Dichter's colleague, Louis Cheskin, also discussed such

\footnotetext{
* Correspondence: charles.spence@psy.ox.ac.uk

Department of Experimental Psychology, Crossmodal Research Laboratory, University of Oxford, South Parks Road, Oxford OX1 3UD, UK
}

shape-taste associations. He was particularly interested in how they could be utilised by marketers in the design of product packaging to set up the right, or appropriate, expectations in the mind of the consumer (for example, Cheskin [4]). A number of beverage products already appear to use angular red shapes, frequently a star, but sometimes also a triangle or pyramid, in order to subconsciously signal to the consumer that the contents of the packaging are carbonated, and/or bitter-tasting. Why else, one might ask, do so many brands of sparkling water adorn their product packaging with such symbols (Figure 1A, B, and C)? Well, it turns out that these shapes may be more than purely symbolic.

On the one hand, it could be argued that the triangular shape on the front of the Apollinaris bottle (Figure 1B) is actually meant to symbolise a mountain. One could also point to the fact that stars are commonly used to recognize prize-winning, high quality, and/or success in whatever they are associated with. Hence, one might think that this is the reason why such shapes appear so

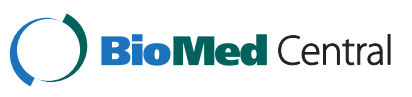




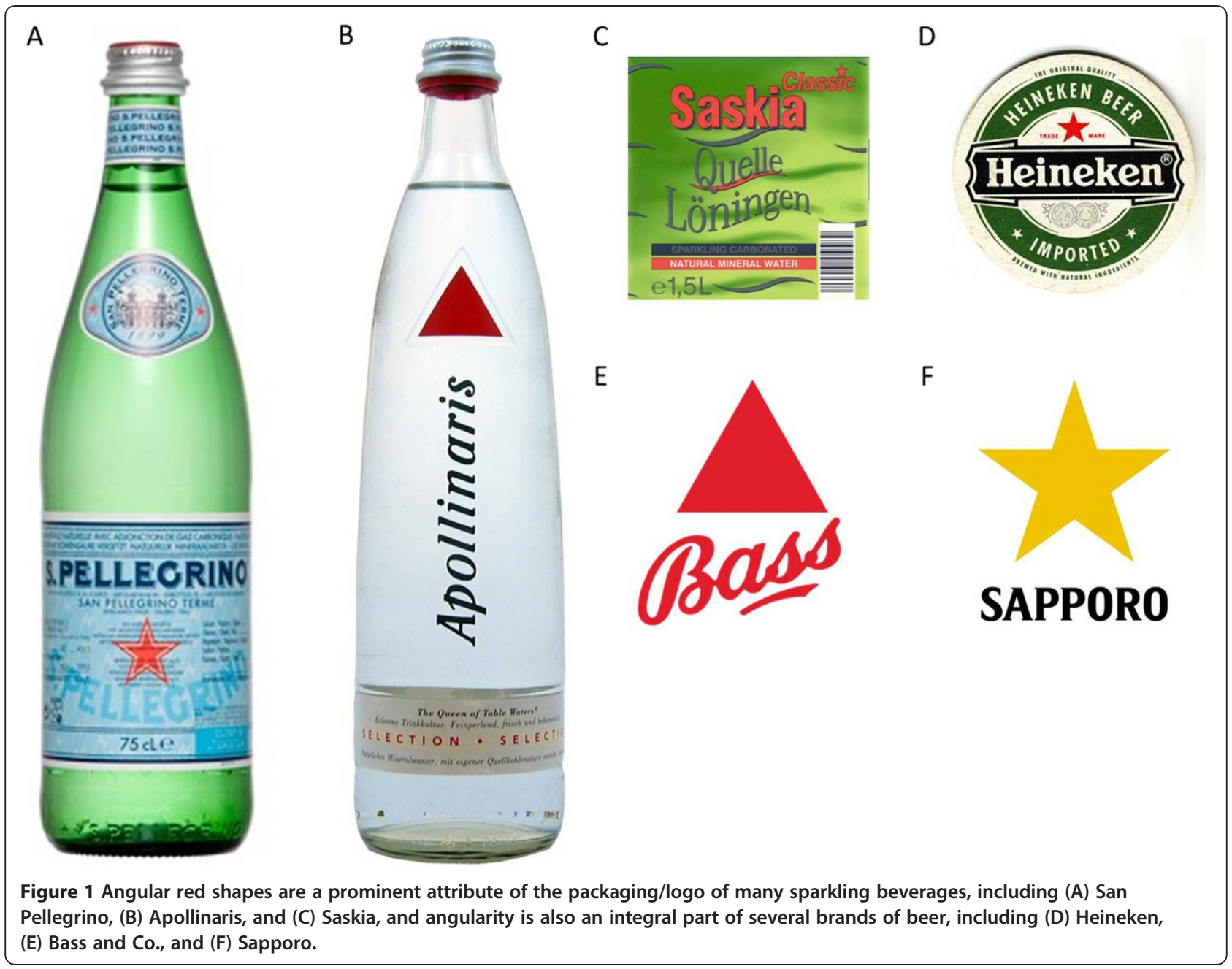

frequently on the labelling of bottled waters. However, the key point to note here is that such angular shapes seem to appear much more frequently on the front (not to mention the sides, back, and top) of carbonated waters than on the packaging of still waters. Should this latter observation turn out to be statistically robust, it would suggest that some form of shape symbolic relation between angularity and carbonation may be at play over and above any other semantic meanings that might be associated with such recognizable angular forms.

Heineken, one of the major producers of beer, another carbonated alcoholic beverage, has also incorporated the red star as an integral part of the company's logo (Figure 1D). In this case, however, it turns out that the shape-symbolic correspondence between carbonation and angularity was not dreamt up by Madison Avenue's marketing guru, as Cheskin [4] was sometimes described. It is, in fact, an old Dutch brewer's symbol that originated from a prize winning/high-quality assessment in the brewer's early days ([5]). Similarly, one of the first trademarks to be registered in the UK back in 1876 was the angular red triangle on Bass and Co.'s 'Pale Ale' [6] (Figure 1E). Sapporo, in Japan, has also incorporated a prominent star (originally red, though they recently changed the colour to a sandy yellow) on the front of their logo (Figure 1F). And, according to the company's Italian website (www.sanpellegrino.com [7]), the red stars that appear up to seven times on some bottles of San Pellegrino sparkling mineral water have been an integral part of the design of this highly successful product's packaging for more than a century now. Although these examples are admittedly anecdotal, when taken together, they do at least suggest that the successful use of shape symbolism in packaging design may help to give products a slight but significant, not to mention long-lasting, competitive advantage in the marketplace [8].

Although such non-verbal signals (for example, abstract forms) normally go unnoticed by the consumer's conscious mind, that does not necessarily mean that such cues are not picked-up and utilized by the 
unconscious mind [9]. Indeed, a quick walk down the aisles of the local supermarket provides sufficient evidence to suggest that shape symbolism effects such as those just described are not uncommonly used by marketers and graphic designers, either deliberately or otherwise. The reason for this may be to convey nonverbal information to the consumer about the sensory properties (for example, carbonation, bitterness, sweetness, and so on) of packaged food and beverage items. One explanation for such patterns in the marketplace is that they provide evidence of 'intelligent design' on the part of the creative teams involved. On the other hand, however, it could also be argued, albeit rather speculatively at this stage, that the use of such shape symbolism in connection with a number of popular and longlasting food and beverage products/brands may actually reflect nothing more that the 'survival of the fittest'; that is, product packaging, or brand logos, whose shape symbolic associations do not match the sensory attributes of the product itself are less likely to survive for long in the highly competitive marketplace than those that do. Thus, those examples where the designer or design team intuitively happened to get it 'right' (for example, the prominent red stars associated with the packaging of San Pellegrino sparkling water), or at least to come up with a 'consensual' design [10], may simply end up staying on the shelves for longer, that is, selling better. Of course, if this suggestion were to be correct, then one might speculate that researchers and marketers may well find inspiration regarding the existence of heretofore undiscovered (or at least undocumented) shape symbolic correspondences simply by looking in the marketplace for any statistical regularities in the imagery (for example, along the angular versus rounded continuum) associated with different tastes, oral-somatosensory attributes, and/or flavours in food and/or beverage products.

In what follows, we start by briefly highlighting the origins of laboratory research on shape symbolism. We then go on to summarise the data from a number of recent studies, both published and unpublished, in which cross-modal correspondences between shapes (or angularity/curvilinearity) and the sensory attributes of a variety of different food and beverage items have been documented. We review the latest evidence from those studies that have demonstrated that the shapes that consumers are exposed to in a food or beverage consumption context can actually change their responses to a variety of foodstuffs. Finally, we outline a number of explanations for such cross-modal correspondences that have been put forward over the years. Note here that relevant shape information can be conveyed by, or associated with, any abstract imagery present on the label or logo, the shape of the label, or even the very shape of the product packaging itself [9,11-17].

\section{Laboratory research on shape symbolism}

The phenomenon of shape symbolism was originally documented by psychologists and linguists back at the end of the 1920s $[18,19]$, though note that at that time it was referred to as sound (rather than shape) symbolism. Sound symbolism is the name given to the idea that certain speech sounds may signify (or be associated with) certain attributes in that which they refer to $[2,20]$. While research on the topic of sound symbolism goes back at least as far as Plato [21], the dominant view, until recently, seems to have been that the link between the signifier and the sign is arbitrary [22]. However, while this is often the case, a growing body of research now suggests the existence of a number of sound symbolism effects in language [20,23]. Shape symbolism refers to the idea that people associate certain attributes (in this case, attributes of food and beverage products) with specific shapes, typically varying in their size and or angularity/degree of curvature. Both sound and shape symbolism can therefore be seen as specific forms of cross-modal correspondence [2]. It was the linguist Edgar Sapir [19] who first reported that if asked to assign each of the meaningless names 'Mil' and 'Mal' to a large and a small table, then the majority of people say that the word 'Mal' was more appropriate for the larger table (thus demonstrating a cross-modal correspondence between the size of objects and specific speech sounds). Subsequently, the association between the ' $i$ ' sound and smallness has been demonstrated in many different cultures/languages across the world, for example, Newman [24] (though see Diffloth [25] for a dissenting voice).

Perhaps more relevant when it comes to the use of shape symbolism on product packaging are the findings reported by the German psychologist Wolfgang Köhler [18]. He noted that when given the meaningless names 'Baluma' and 'Takete', the majority of people match the 'rounded' sounds of 'Baluma' with the more organic shape, and the 'harsher' sound of the plosive stops in 'Takete' with the angular star-like shape instead (Figure 2). When he later changed 'Baluma' to 'Maluma', to avoid any unwanted potential associations with the word balloon, he obtained exactly the same pattern of results [see Köhler [26], Nielsen and Randall [27], Ramachandran and Hubbard [28], and Bremner et al. [29]]. Until very recently, no one seems to have given much thought to the possibility that cross-modal correspondences might also exist between shapes and tastes or flavours (though see Fónagy [30,31], for a solitary exception). The absence of serious scientific interest in the existence of cross-modal correspondences between shapes and tastes, the oralsomatosensory attributes of foodstuffs, and flavours contrasts with the already-mentioned (albeit unsubstantiated) suggestions that have occasionally appeared in the 


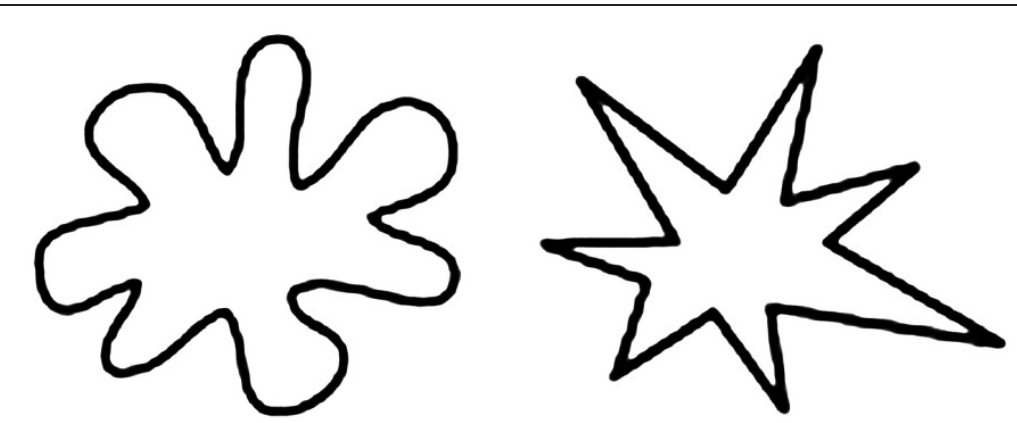

Figure 2 Which of these shapes is called 'Baluma;' (or 'Maluma' or 'Bouba') and which is called 'Takete' (or 'Kiki' [25]). The majority of people around the world pair the more organic amoeba-like shape with the 'rounded' speech sounds of 'Baluma'.

marketing/packaging press over the last 50 years or so (for example, see Dichter [3], Cheskin [4], and McNeal [32]).

\section{Assessing the shape symbolism of tastes and flavours}

A recently published series of experiments has, though, now started to document the existence of a number of robust and easy-to-demonstrate crossmodal correspondences between shapes and the various sensory properties of a variety of real food and beverage items (see references [7,33-38]). So, for example, it has been shown that people tend to match sweet-tasting foods with organic (and rounded) shapes while matching more angular shapes with bitter- and sour-tasting foodstuffs (see Table 1 for a summary of what is currently known about shape symbolism in the food and beverage sector). Carbonation, as in a sparkling beverage, is also matched by consumers with more angular shapes (such as a star). These cross-modal associations, or correspondences, can

Table 1 Summary of shape symbolic associations with food and beverage products

\begin{tabular}{lll}
\hline Angular shapes & Organic shapes & Study \\
\hline Cranberry jam & Blueberry jam & Gallace et al. [33] \\
Mint chocolate & Brie & \\
Salt and vinegar crisps & Regular crisps & \\
Dark chocolate & Milk chocolate & Ngo et al. [34] \\
Sparkling water & Still water & Spence and Gallace [17] \\
Maltesers & Rolos chocolates & \\
Cranberry juice & Brie & \\
Sparkling water & Still water & Ngo et al. [37] \\
Dark chocolate & Milk chocolate & Ngo and Spence [34] \\
Solid mint chocolate & Mint fondant & \\
Tunworth cheese & Lancashire Cheddar & Spence et al. [38] \\
Keen's Cheddar & Stawley goat's cheese & (unpublished work) \\
& Leipäjuusto cheese & \\
Bitter tastes & Sweet tastes & Dichter [3] \\
\hline
\end{tabular}

normally be demonstrated in relatively small, and easy to conduct, studies. Such experiments typically involve testing no more than 10 to 20 participants, each giving a single response to each food or beverage on an anchored Visual Analogue Scale (VAS).

While the majority of research assessing the shape symbolism of tastes and flavours has been conducted with actual consumers sampling real food and beverage products, we have recently demonstrated that at least certain of these results can also be obtained simply by instructing people to imagine the taste of particular foods and/or beverages. Thus far, mentally imagining the taste of a food has been shown to work for relatively simple, or stark, food comparisons, such as that between still and sparkling water, or between milk and dark chocolate. What is more, under such circumstances, Internet-based data collection appears to be just as reliable at highlighting the cross-modal correspondences between angularity and oral-somatosensory texture as more traditional laboratory-based data collection techniques $[35,37]$. Taken together, these simple techniques are now allowing academic researchers, not to mention sensory marketers, to rapidly assess just how many cross-modal correspondences there are between shapes, primarily varying in terms of their angularity, and the tastes, flavours, and oral-somatosensory attributes of foodstuffs [9].

Below, we briefly summarize some of the key results to have emerged from the latest research on the topic of shape symbolism in the food and beverage sector. In one study, Ngo et al. [34] provided evidence of the existence of a cross-modal correspondence between the angularity of visually presented shapes and the bitterness of chocolate samples. The participants in this study tasted three samples of commercially produced chocolate that varied in their cocoa content: one 30\% cocoa milk chocolate, another 70\% cocoa dark chocolate, and the third 90\% cocoa dark chocolate. After tasting each sample, the participants were instructed to place a mark at the 
appropriate point along an analogue line scale anchored at one end by an organic shape and at the other end by an angular shape. The results revealed that as the cocoa content of the chocolate samples increased, so the participants tended to mark a point on the scale that was closer to the angular-shaped end of the line (Figure 3). Note that in order to control for any bias that participants might have toward responding on one side of the scale $v s$. the other (a phenomenon known as pseudoneglect-shown when neurologically normal individuals systematically mis-bisect the mid-point of a line shown visually [39]), Ngo et al. sometimes presented the more angular anchor on the left of the scale and at other times on the right of the scale instead. Crucially, the relative positioning of the shapes on the left $v s$. right of the scale does not seem to have a noticeable effect on the pattern of results observed in this kind of study.

A follow-up study [35] both confirmed these findings and additionally revealed that consumers consistently matched milk and mint fondant chocolates (50\% cocoa dark chocolate with a smooth and creamy mint filling) with organic shapes, while matching dark (70\% cocoa) and solid mint (50\%) chocolates with angular shapes instead. Note that the taste/flavours of the mint fondant and solid mint were essentially the same. The key distinction between the two foodstuffs was in terms of the texture, with mint fondant being creamy and soft, and solid mint having a somewhat harder texture. The results of this latter study therefore highlighted the key role that oral-somatosensory texture can play in determining the cross-modal correspondences that consumers exhibit for everyday foodstuffs such as chocolate.
Elsewhere, researchers have demonstrated that consumers match the oral-somatosensory properties of Maltesers (honeycomb-centred milk chocolate produced by Nestlé) with more angular shapes while matching Rolos (Nestlé) and Caramel Nibbles (Cadbury; both soft caramel filled milk chocolates) with more organic shapes instead [7]. Once again, given that the chocolate coating of these products was very similar, the shape symbolic relationship would appear to have been driven by the crunchy honeycomb versus soft caramel centres of these chocolate products (that is, by the oral-somatosensory texture of the products).

Deroy and Valentine [36] recently examined crossmodal correspondences for several different kinds of beer (6.4\% alcohol Adelscott, 5.5\% alcohol 1664 Blanche, and $4.8 \%$ alcohol Bitburger) and various $2 \mathrm{D}$ and $3 \mathrm{D}$ shapes. The participants in this study were given a total of 34 shapes from which to choose (Figure 4). The results demonstrated that the Adelscott beer was considered sweeter-tasting than the other beers and was incidentally matched with more rounded, voluminous shapes, while participants judged the Bitburger to be more bitter-tasting and matched it with angular shapes instead. It is, though, worth noting here that the results of the two studies that have used a wide variety of possible shapes [36,40] have not, as yet, provided any particularly clear results; nor, we would argue, have they provided any especially strong justification for using so many possible stimuli in future shape symbolism research in the food and beverage sector. Hence, for the moment at least, we would be tempted to advocate the use of the simpler VAS contrasting an organic/rounded shape on the one hand with an angular

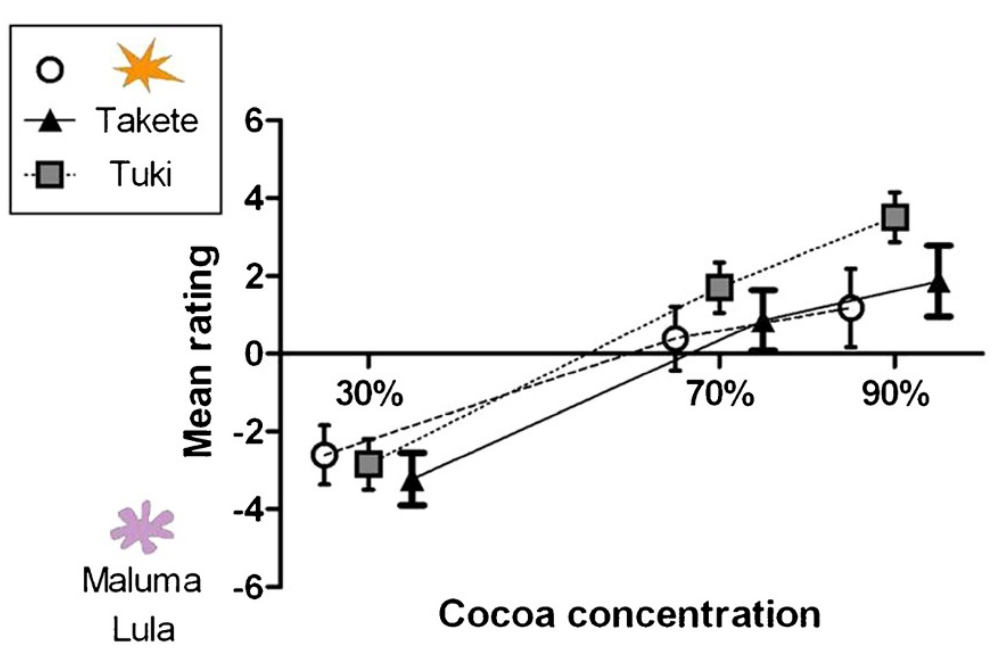

Figure 3 Results from a study conducted by Ngo et al. [34] demonstrating both sound and shape symbolism effects with increasing bitterness (for example, as the cocoa content increases in the chocolate) being matched with more angular shapes and words starting with a harder plosive sound (' $\mathbf{t}$ ' in this case). The units on the Y-axis indicate the distance (in $\mathrm{cm}$ ) along the 10-cm line scale, with 0 reflecting the centre point. Figure adapted and reprinted from Ngo et al. [34], Figure 2, with permission. 

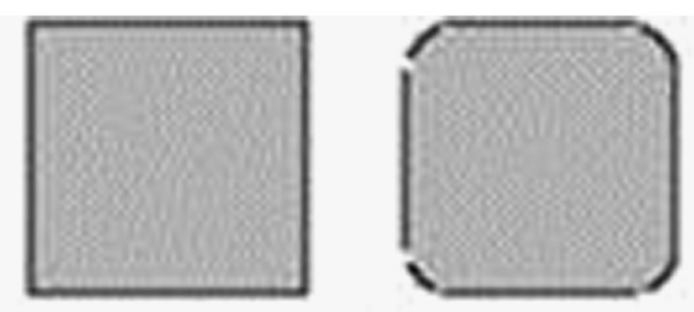

1
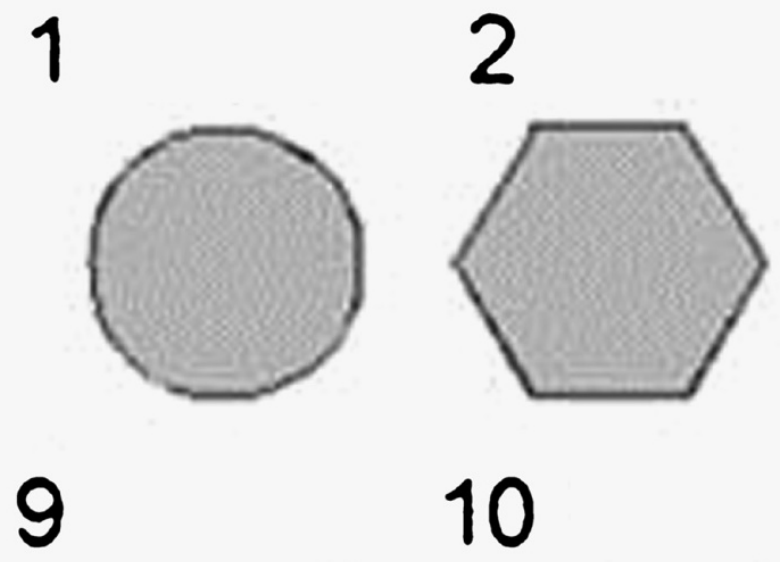

10
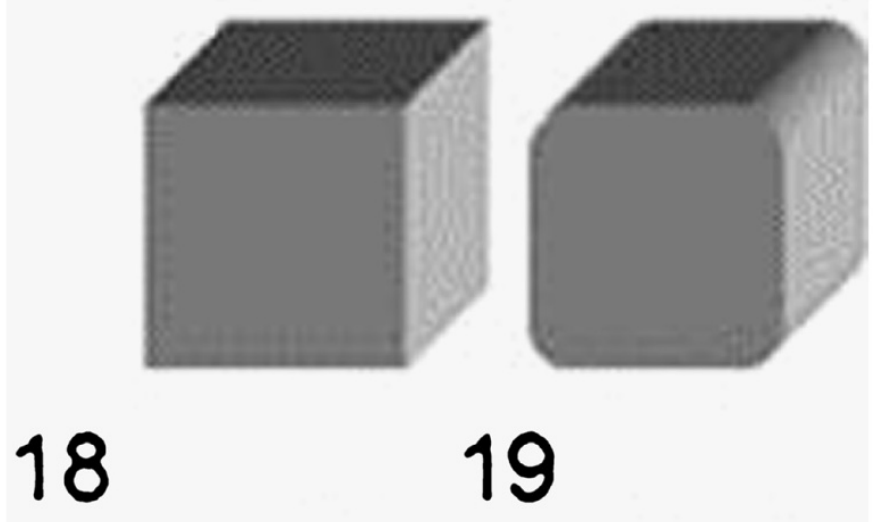

19
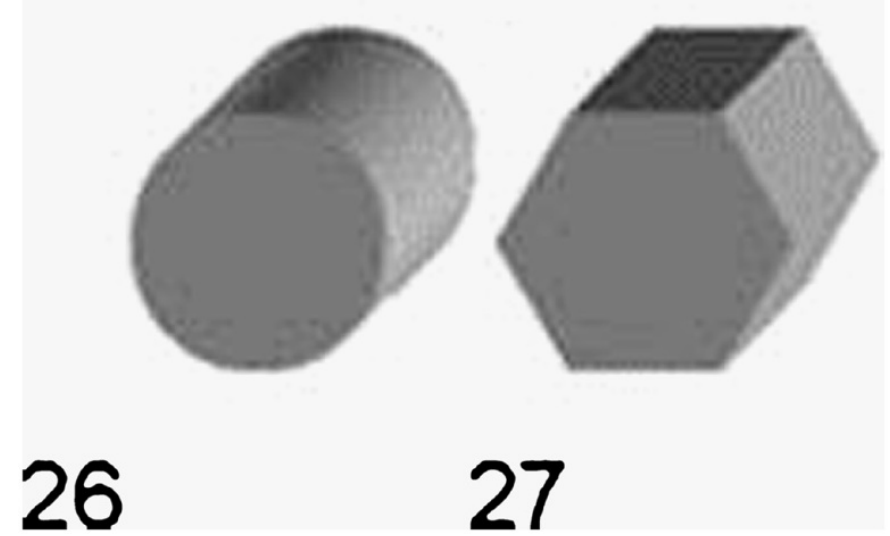

Figure 4 Figure showing a sample from the 34 different two- and three-dimensional shapes (based on a range of shapes originally introduced by Cytowic and Wood [40]) used in Deroy and Valentin's [36] recently published study in order to assess the properties of three different beers (Bitburger, Adelscott, and 1664 Blanche). Modified and reprinted from Deroy and Valentin [36], Figure 2, with permission. 
shape on the other, at least until we understand more about the key drivers underlying shape symbolism effects in the food and beverage sector.

Recently, Spence et al. [38] extended the exploration of shape and sound symbolism to the more complex flavour profiles associated with various aged cheeses. These researchers examined each separate component of the flavour Gestalt of the cheese by having participants separately rate the gustatory, olfactory, and oralsomatosensory attributes on the angular vs. organic shape response scale (Figure 5). The strong and pungent flavours of Tunworth, a Camembert-style cheese, and Keen's Cheddar were matched by participants with the angular shape. By contrast, the milder flavours of Stawley goat's cheese and Lancashire Cheddar were rated as being more organic in shape. The results suggested that participants based their responses primarily on the taste/flavour (note that although participants were asked to report on taste, normal consumers often confuse taste and smell) rather than on the smell or texture of the cheeses that they were evaluating. Similar results were also obtained from cheese experts (for example, cheese mongers) and from typical store consumers. As such, the shape symbolism approach to describing cheeses may hold the potential to provide a more accessible means for individuals, experts and consumers alike, to talk about the qualities of a product such as cheese. A follow-up study conducted recently on a group of Finnish participants demonstrated that Leipäjuusto, a mild cheese that tends to 'squeak' against the teeth when a consumer bites into it, was consistently matched with the organic shape. The latter results once again suggest that taste was the leading contributor to participants' shape symbolic correspondences.

It is worth noting in passing here that many people often describe cheeses as having a 'sharp' taste (see Williams [41] and Spence et al. [38]). In this case, the synaesthetic use of the adjective sharp, which is normally only used to refer to the tactile attribute of an object (according to the dictionary definition, the term 'sharp' refers to something with a thin cutting edge or a sharp point), appears to be used by people to describe the noticeable acidity that is a prominent feature of many cheeses. This is especially true of British Cheddar cheeses. Wine aficionados have also been known to refer to certain pleasant wines as well rounded $[42,43]$. Here, though, it is rather less clear whether the shape descriptor 'rounded' is being used in a literal sense, or rather just as a colloquial (or metaphorical) means of expressing the generally pleasing and well-balanced nature of the particular example of fermented grape juice under consideration.

\section{Using shape symbolism to set consumer expectations in the food and beverage sector}

It is our contention that the appropriate use of shape symbolism on product packaging, especially in the food and beverage sector, can be used to help set up the right sensory expectations in the minds of consumers. It has been suggested that the colours and shapes on product packaging can be just as, if not more, important than any text/descriptions in terms of setting up, consciously or otherwise, expectations about a product's likely sensory qualities $[44,45]$. This may be especially true given how

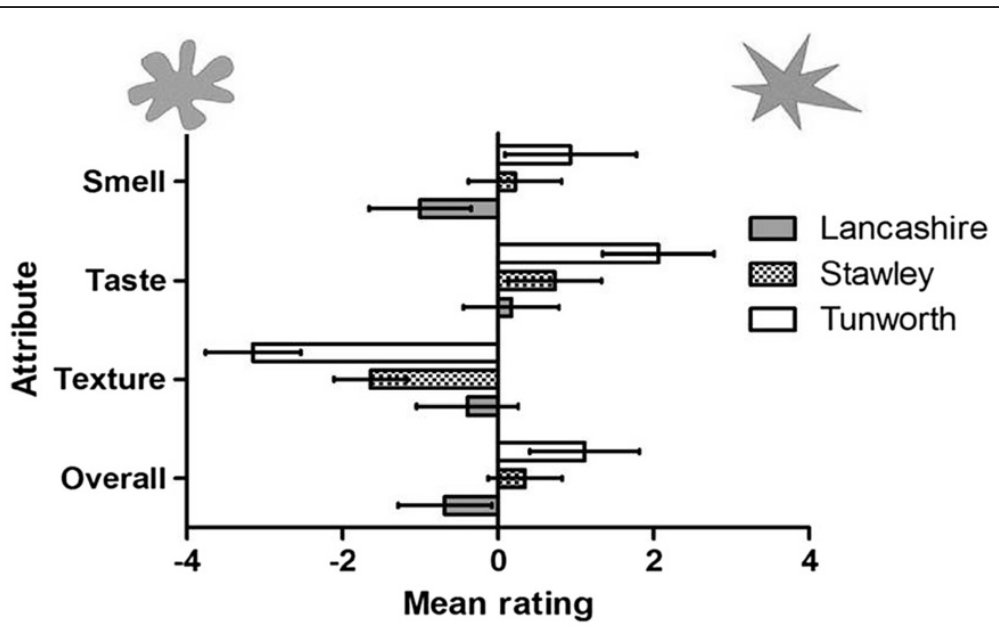

Figure 5 Figure showing the results of recent research in which participants had to rate the individual attributes of a range of aged cheeses (aroma, taste/flavour, oral-somatosensory texture, and overall experience) using response scales anchored by the organic and angular shapes. The results show that the taste element of the overall flavour drove participants' cross-modal associations. Ideally, the positioning of the anchors for these scales (for example, on the left or right of the page) should be randomized in order to control for any left-right biasing effects [39]. 
little attention consumers give to certain kinds of labels (for example, back labels on wine bottles [46-48]). The theory here is that under the majority of conditions, molecular gastronomy restaurants excepted [49], consumers prefer a product if its taste, aroma, flavour, and/or oralsomatosensory attributes match their prior sensory expectations [50-51]. Marketers and graphic designers may, then, be well advised to try and set up the appropriate expectations through any shape displayed on the packaging (Figure 6). In the section that follows, we will see how viewing shapes (for example, as on packaging) might be expected to influence the actual taste of the product consumed. Relevant here are the results of a survey conducted a few years ago by AC Nielson Co. on fastturnover consumer products. The suggestion was that more than $50 \%$ of new product failures can be attributed to there being some sort of mismatch, or unintended interaction, between the product and its packaging [6].

Explaining the existence of cross-modal correspondences between shapes and the sensory attributes of foods and beverage products?

According to a large body of older empirical research using the semantic differential technique [53], the meaning of concepts/words can be mapped by assessing people's responses to a small number of scales that are anchored by pairs of polar opposite terms, normally adjectives (for example, good $v s$. bad, old $v s$. young, and so on). The most popular (discriminative) dimensions to be extracted from the presentation of such scales to consumers were activity, evaluation, and potency. Note that evaluation refers to the pleasantness/unpleasantness of the stimuli. The idea is that people may simply use the angular/rounded response scale as a proxy to indicate how pleasant they find the taste, flavour, and/or oralsomatosensory texture of a food or beverage product. Relevant here is the fact that people tend to prefer rounded over more angular shapes [54]. Certainly there are grounds for suggesting that mapping pleasantness might provide part of the answer to the underlying explanation for the existence of shape symbolism in the food/beverage sector. Note that angularity, bitterness, and carbonation are all initially disliked as stimuli $[55,56]$. The common meanings associated with different kinds of sensory stimuli [57-60] may therefore provide a possible explanation for at least certain of the shape symbolism effects that have been documented in the food and beverage sector to date. The affective value, or pleasantness, of sensory stimuli therefore provides one way in which the 'meaning' of very different types of sensory stimuli could be matched. However, that said, the latest evidence assessing the cross-modal correspondences that people have with dark chocolate, a foodstuff that some people find very pleasant while others rate as unpleasant, suggests that pleasantness is unlikely to provide the whole story here [61].

It is also worth noting that the term sparkling, often used in English-speaking countries to refer to carbonated water, may also lead to specific associations with stars that sparkle. However, while this more semantic explanation of shape symbolic matching works when it comes to trying to explain the cross-modal association between the star-

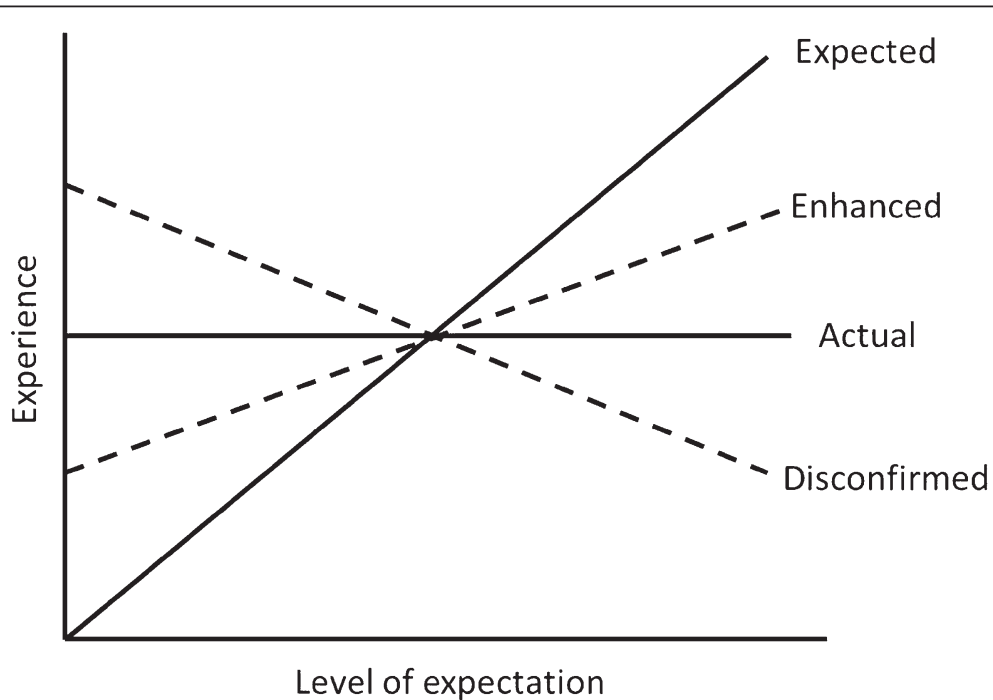

Figure 6 Figure showing the predicted effect of various degrees of 'disconfirmed expectation' on overall product experience (modified from Schifferstein [51]). The basic idea here is that if the expectation set up (for example, by the shape symbolism on the packaging) is a little better than the actual experience delivered by the product, then the consumer experience may be enhanced. However, if the difference between expectation and actual experience is too great then what you end up with is disconfirmed expectation. 
shape and carbonated water, the fact that participants show an equally strong tendency to match carbonation with a triangle as with a star, argues against this being the most appropriate explanation for this particular crossmodal correspondence. Thus, it seems to be something about angularity, per se, rather than any concrete meaning that can be attached to the abstract shapes embodying that angularity that is doing the work here.

In terms of shape, McNeal [32] has suggested (although without providing any evidence) that triangles constitute lively shapes and hence are good for sparkling beverages. At least intuitively, sparkling beverages, acidity, and crunchy textures in food would all seem to be associated with activity. By contrast, still water, sweet tastes, and softer textures, as in the case of soft caramel, would seem to be more passive kinds of stimuli instead. Hence, it could be argued that the similar meaning associated with shapes and flavour experiences associated with foods and beverages might underlie at least certain examples of the sound symbolic mappings that have been documented to date (for example, the mapping between angular shapes and carbonation). One might also wonder whether some sort of metaphorical mapping can also be put forward to help explain shape symbolic mappings in the food and beverage sector [30,31,62-65].

Given that angularity on product packaging does indeed appear to be linked to certain carbonated beverages (specifically carbonated water and beers/lagers), it becomes difficult to ascertain whether consumers, when asked to match an angular $v s$. rounded shape with carbonation in sparkling water, say, are basing their response on the statistical correlations present in the marketplace, or on some deeper (possibly metaphorical) association between angularity and taste/flavour. In order to try and address this question, Bremner et al. [29] recently conducted a study of shape symbolism with the remote Himba from Kaokoland in Namibia. This group have no written language, nor access to supermarkets/advertising, and so on. These researchers asked whether this group would exhibit the same kinds of cross-modal correspondences as the Western participants tested in the majority of the studies reported to date. Interestingly, while this group demonstrated the basic bouba/kiki effect $[18,28]$, they showed no significant association when it came to assessing the angular $v s$. rounded shapes to samples of sparkling $v s$. still water. What is more, when it came to assessing three samples of chocolate varying in their cocoa content, the Himba actually showed the opposite pattern of results to Western participants. That is, they actually matched bitter tastes with rounded forms. These results therefore demonstrate that at least certain shape symbolic associations between tastes, flavours, and the oral-somatosensory attributes of food and beverage products are culture specific. These results are also consistent with the suggestion that
Western participants' shape symbolic responses to the tastes, flavours, and oral-somatosensory attributes of foods may be learnt (no matter whether this is done explicitly or implicitly) from the statistics of the marketplace.

Finally, in the future, it will be important to probe whether the amoeba-like and star-like shapes used in many of the studies on shape symbolism are necessarily the most appropriate for research in this area. These shapes have been inherited, more or less unchanged, from Köhler's [18] early work [7,28]. One might therefore ask, especially in light of certain comments from the marketers [3], whether these shapes are any more (or less) appropriate than other shapes, such as a circle or triangle, say [59]. Or, in other words, is it anything more than an accident of history that researchers do not use a circle and a triangle or square instead of the amoeba-like shape and the star? One might also ask what the relevant attribute of the shapes that are matched to the oral-somatosensory attributes of food really is. Research using more complex arrays of shapes may help to provide an answer here [see Cytowic and Wood [40] and Hanson-Vaux et al. [66]]. As we have seen already, one possibility is that people may match stimuli across the modalities in terms of their pleasantness $[53,61,67]$.

In summary, then, a number of different plausible explanations for the existence of reliable cross-modal associations between the angularity of shapes on the one hand, and the taste and flavour of food and beverage products on the other, can be postulated. While several explanations have gained some degree of empirical support, it is important to note that there may simply not be a single explanation for all such cross-modal matching effects $[1,2]$.

\section{Does shape symbolism influence the sensory- discriminative properties of food and beverage items?} Although there is currently little information directly relevant to this question, those studies that have been published do indeed suggest that shape symbolic sensation transference $[4,16]$ can occur. The participants in an as yet unpublished study by Gal et al. [17] first had to judge which of three simultaneously presented (and similarly sized) shapes occupied the largest surface area. Next, they had to taste a piece of Cheddar cheese. Those participants who had evaluated three angular shapes rated the cheese as tasting significantly sharper (by around 7\%) than another group of participants who had just evaluated three organic shapes instead. While a relatively large number $(>200)$ of participants had to be tested in this study in order to generate a result that was only just statistically significant, the potential implications of these findings in terms of the use of shape symbolism in/on product packaging could well be worth 
pursuing. Think only of the much larger number of 'participants' who are likely to interact with any moderately successful product launched into the marketplace than were tested by Gal et al. Meanwhile, Becker et al. [12] have recently shown that the curvature of a product's packaging can also affect a consumer's rating of the taste of, in this case, yoghurt, even when the shape of the container was only seen on a computer monitor while the yoghurt itself was consumed from a tray.

The participants in a study by Seo et al. [68] had to match each of eight food odours (guava, honey melon, mint, Parmesan cheese, pepper, truffle, vanilla, and violet) with one of 19 different abstract symbols (Figure 7), varying in shape from those that were more organic to those that were more angular. The participants reliably matched certain shapes to particular odours: as Seo et al. put it, The odors generally regarded as being pleasant (e.g., vanilla, banana, violet, honey melon, and mint) were paired with circle-or curve-shaped symbols, whereas, the odors judged generally as being unpleasant (e.g., Parmesan cheese, truffle, and pepper) were paired with squareor angular-shaped symbols. In the second part of this study, Seo and colleagues documented significant differences in odour pleasantness and intensity ratings for two of the odours, those smelling of violet and of Parmesan cheese, when they were presented together with an abstract shape that had been judged as being congruent than when they were presented with an incongruent shape, or else with no visual stimulus at all. In particular, the odour of violet was rated as being more intense and more pleasant while Parmesan cheese odour was rated as being less pleasant (when presented with a congruent as compared to an incongruent symbol). Thus, the pairing of a congruent shape with the odour gave rise to a more extreme perceptual response in terms of intensity and pleasantness. That is, those odours that were considered pleasant to begin with became even more pleasant and more intense when presented with the congruent symbol, while those odours that were individually rated as unpleasant became even more unpleasant with the presentation of the congruent symbol.

Participants' brain responses were also measured using olfactory event-related potentials (ERPs). Using this technique, Seo et al. [68] were able to demonstrate that this particular cross-modal correspondence between abstract visual shapes and odours was influencing the neural responses of participants at a relatively early stage of information processing. In particular, the $\mathrm{N} 1$ component had both a higher amplitude and a shorter latency on trials that were cross-modally congruent as compared to those that were cross-modally incongruent in terms of their shape symbolism [69,70]. Given that these crossmodal interactions occurred so soon after stimulus onset, Seo et al.'s results suggest that the presentation of the abstract shape was having an effect on participants' perception of the odour, rather than just on their subsequent rating of that odour experience [71]. These results involving expectations set by the use of shape symbolism are consistent with other research demonstrating the impact of other ways of inducing product expectations on product perception [72].

\section{Conclusions}

The last few years have seen rapid growth in our understanding of, and evidence for, cross-modal correspondences between shapes and tastes, flavours, and the oral-somatosensory attributes of food and beverage products. Visual inspection of the products currently available

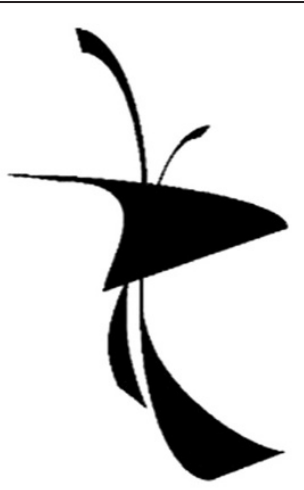

(b) PEA symbol

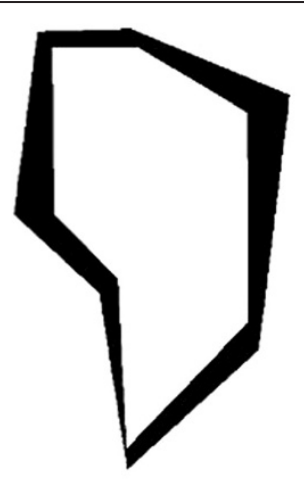

(c) 1-butanol symbol (a) No-symbol (white area)

Figure 7 Abstract symbols/shapes used in Seo et al.'s [68] study. Reprinted with permission from Seo et al. [68], Figure 2. 
in a typical supermarket suggests that these shape correspondences have, on occasion, already been used. Though, as we saw earlier, whether this is as a result of intuition on the part of the marketers or merely an example of 'survival of the fittest' in the marketplace is currently hard to say. (Of course, it could also be the case that when a particular shape correspondence is (un)successful on the market that it will shape the future intuitions of the marketers.) That said, the research reviewed here clearly demonstrates how widespread and easy to assess such cross-modal correspondences are, even in the food and beverage sector. The effects reported here also appear to be fairly robust, given that very similar cross-modal matching results have been obtained when the same foodstuffs were assessed in various different studies. Shape symbolism can extend from everything from the shape of labels to the shape of the containers themselves [12,16]. Having demonstrated an extensive array of shape symbolism effects in the food and beverage sector in Western participants, researchers will obviously need to assess how widespread such effects are in different cultures/markets in the future (Bremner et al. [29] and Heinrich et al. [73]).

The available evidence provides some limited support for the suggestion that the expectations that are set up by shape can influence people's product perception $[12,17,68]$. At present, though, the effects of capitalizing on crossmodal correspondences between shape and taste/flavour for commercial applications definitely needs longer-term follow-up studies in order to demonstrate the potential implications of shape symbolism to marketing in the food and beverage sector. In the future, it will also be crucial to demonstrate that the use of such shape symbolism impacts on consumers' choice between products in more realistic environments, such as the supermarket aisle. In terms of the future of this kind of research, to the extent that we taste what we expect to taste, both in terms of the sensory discriminative and hedonic properties of foods and beverages, one could imagine using shape symbolism in order to enhance sweetness or saltiness, say, when the actual formulation of various popular brands has been modified in order to meet the latest health targets. This normally calls for a reduction of these tasty ingredients, such as salt, sugar, carbonic acid $\left(\mathrm{H}_{2} \mathrm{CO}_{3}\right)$, and fat, a reduction that often leads to complaints from brand-loyal consumers [74]. It will also be interesting to investigate whether any shape symbolic expectations can be maximised by making sure that, where possible, the shape symbolic associations of the shape of the packaging, label, and even logo convey a congruent message. Here, one might already think of the angular bottle and label shape used on the Listerine bottle versus the rounded bottle and label used for Scope, both brands of mouthwash [75]. What is certainly clear is that there is growing interest in this area from academic researchers [76-78].
In conclusion, we believe that the appropriate utilization of shape symbolism in the marketplace may have a number of advantages when compared to other more traditional marketing techniques [9]: On the one hand, shape symbolism effects are more likely to work in the global marketplace, since they are typically unaffected by language [that said, it currently remains a question for future research to determine which cross-modal correspondences are universal and which are more culture specific (see Diffloth [25] and Bremner et al. [29]]; on the other hand, the use of shape symbolism on product packaging also seems to have the advantage that it can set up sensory expectations in the mind of the consumer whether or not they happen to be paying attention to the meaning of the shapes that they are exposed to.

\section{Competing interests}

The authors declare that they have no competing interests.

\section{Authors' contributions}

$\mathrm{CS}$ and $\mathrm{MN}$ both contributed to the writing of this review. Both authors also read and approved the final version of the manuscript.

\section{Acknowledgements}

MN would like to thank The Clarendon Fund, Oxford University, for funding her PhD research. The two authors contributed equally to the writing and research involved in this article.

Received: 7 October 2011 Accepted: 15 February 2012

Published: 2 July 2012

\section{References}

1. Parise CV, Spence C: Audiovisual crossmodal correspondences. In Oxford Handbook of Synaesthesia. Edited by Simner J, Hubbard E. Oxford: Oxford University Press; in press.

2. Spence C: Crossmodal correspondences: A tutorial review. Atten Percept Psychophys 2011, 73:971-995.

3. Dichter E: The strategy of selling with packaging. Package Eng Mag 1971, July:16a-16c.

4. Cheskin L: Secrets of marketing success: An expert's view on the science and art of persuasive selling. New York: Trident Press; 1967.

5. The Dutch touch [http://175proof.com/triedandtested/the-dutch-touch/].

6. Sacharow S: The package as a marketing tool. Radnor, PA: Chilton Book Company; 1982.

7. Spence C, Gallace A: Tasting shapes and words. Food Qual Prefer 2011, 22:290-295.

8. Miller $C$ : The shape of things: beverages sport new packaging to stand out from the crowd. Market News 1994, 28:1-2.

9. Spence C: Managing sensory expectations concerning products and brands: capitalizing on the potential of sound and shape symbolism. J Consum Psychol 2012, 22:37-54.

10. Koriat A: Subjective confidence in one's answers: the consensuality principle. J Exp Psychol Learn 2008, 34:945-959.

11. Ares G, Deliza R: Studying the influence of package shape and colour on consumer expectations of milk desserts using word association and conjoint analysis. Food Qual Prefer 2010, 21:930-937.

12. Becker L, Van Rompay TJL, Schifferstein HNJ, Galetzka M: Tough package, strong taste: the influence of packaging design on taste impressions and product evaluations. Food Qual Prefer 2011, 22:17-23.

13. Overbeeke CJ, Peters ME: The taste of desserts' packages. Percept Motor Skill 1991, 73:575-580.

14. Smets GJF, Overbeeke CJ: Expressing tastes in packages. Design Stud 1995, 16:349-365.

15. Wang RWY, Sun $\mathrm{CH}$ : Analysis of interrelations between bottle shape and food taste. Paper presented at the 2006 Design Research Society, International Conference in Lisbon (IADE); [http://www.iade.pt/drs2006/wonderground/ proceedings/fullpapers/DRS2006_0054.pdf]. 
16. Spence C, Piqueras-Fiszman B: The multisensory packaging of beverages. In Food packaging: Procedures, management and trends. Edited by Kontominas MG. Hauppauge. NY: Nova Publishers; in press.

17. Gal D, Wheeler SC, Shiv B: Cross-modal influences on gustatory perception.

18. Köhler W: Gestalt psychology. New York: Liveright; 1929.

19. Sapir E: A study in phonetic symbolism. J Exp Psychol 1929, 12:225-239.

20. Hinton L, Nichols J: Ohala JJ (Eds): Sound symbolism. Cambridge: Cambridge University Press; 1994

21. Jowett B: Plato's Cratylus with introduction. Rockville, MD: Serenity Publishers; 2009.

22. Saussure F: In Course in general linguistics. Edited by Bally C, Sechehaye A. IL: Open Court; 1983. Translated by Harris R. La Salle.

23. Robson D: Language's missing link. New Sci 2011, 16 July:30-33.

24. Newman SS: Further experiments in phonetic symbolism. Am J Psychol 1933, 45:53-75.

25. Diffloth G: i: big, a: small. In Sound symbolism. Edited by Hinton L, Nichols J, Ohala JJ. Cambridge: Cambridge University Press; 1994:107-114.

26. Köhler W: Gestalt psychology: An introduction to new concepts in modern psychology. New York: Liveright Publication; 1947.

27. Nielsen A, Rendall D: The sound of round: evaluating the sound-symbolic role of consonants in the classic Takete-Maluma phenomenon. Can J Exp Psychol 2011, 65:115-124.

28. Ramachandran VS, Hubbard EM: Synaesthesia - A window into perception, thought and language. J Conscious Stud 2001, 8:3-34.

29. Bremner A, Caparos S, Davidoff J, de Fockert J, Linnell K, Spence C: Bouba and Kiki in Namibia? Western shape-symbolism does not extend to taste in a remote population. Cognition, , in press.

30. Fónagy I: Die Metaphern in der Phonetik [The metaphors in phonetics]. The Hague: Mouton and Co.; 1963.

31. Fónagy I: A research instrument. In Languages within language: An evolutive approach. Edited by Fónagy I. Amsterdam: John Benjamins; 2001:337-357.

32. McNeal JU: Consumer behaviour: An integrative approach. Boston: Little, Brown and Company; 1982

33. Gallace A, Boschin E, Spence C: On the taste of "Bouba" and "Kiki": an exploration of word-food associations in neurologically normal respondents. Cogn Neurosci 2011, 2:34-46.

34. Ngo MK, Misra R, Spence C: Assessing the shapes and speech sounds that people associate with chocolate samples varying in cocoa content. Food Qual Prefer 2011, 22:567-572.

35. Ngo MK, Spence C: Assessing the shapes and speech sounds that people associate with different kinds of chocolate. J Sens Stud 2011, 26:421-428.

36. Deroy $O$, Valentin D: Tasting shapes: investigating cross-modal correspondences. Chemosens Percept 2011, 4:80-90.

37. Ngo MK, Piqueras-Fiszman B, Spence C: On the colour and shape of still and sparkling water: implications for product packaging. Food Qual Prefer 2012, 24:260-268.

38. Jewell G, McCourt ME: Pseudoneglect: A review and meta-analysis of performance factors in line bisection tasks. Neuropsychologia 2000 38:93-110.

39. Spence C, Ngo MK, Percival B, Smith B: Crossmodal correspondences: Assessing shape symbolism for cheese. Food Qual Prefer 2013, 28:206-212.

40. Cytowic RE, Wood FB: Synaesthesia II: psychophysical relations in the synaesthesia of geometrically shaped taste and colored hearing. Brain Cognition 1982, 1:36-49.

41. Williams JM: Synesthetic adjectives: a possible law of semantic change. Language 1976, 52:461-478.

42. Lehrer A: Wine \& conversation. 2nd edition. Oxford: Oxford University Press; 2009.

43. Peynaud E: The taste of wine: the art and science of wine appreciation. London: Macdonald \& Co; 1987. Translated by Schuster M.

44. Singh S: Impact of color on marketing. Manage Decis 2006, 44:783-789.

45. Swientek B: Uncanny developments. Beverage Ind 2001, 92:38-39.

46. Charters $S$, Lockshin L, Unwin T: Consumer responses to wine bottle back labels. J Wine Res 1999, 10:183-195.

47. Bender MM, Derby BM: Prevalence of reading nutrition and ingredient information on food labels among adult Americans: 1982-1988. J Nutr Educ 1992, 24:292-297.

48. Wansink B, Sonka ST, Hasler CM: Front-label health claims: When less is more. Food Policy 2004, 29:659-667.
49. Piqueras-Fiszman B, Spence C: Sensory incongruity in the food and beverage sector: art, science, and its commercialization. Petits Propos Culinaires, 95:74-118.

50. Deliza R, MacFie HJH: The generation of sensory expectation by external cues and its effect on sensory perception and hedonic ratings: a review. J Sens Stud 1997, 2:103-128.

51. Schifferstein HNJ: Effects of product beliefs on product perception and liking. In Food, people and society: a European perspective of consumers' food choices. Edited by Frewer L, Risvik E, Schifferstein H. Berlin: Springer Verlag; 2001:73-96.

52. Yeomans $M$, Chambers $L, B l u m e n t h a l ~ H$, Blake $A$ : The role of expectancy in sensory and hedonic evaluation: the case of smoked salmon ice-cream. Food Qual Prefer 2008, 19:565-573.

53. Osgood CE, Suci GJ, Tannenbaum PH: The measurement of meaning. Urbana: University of Illinois Press; 1957.

54. Bar M, Neta M: Humans prefer curved visual objects. Psych Sci 2006, 17:645-648.

55. Spence C: Multi-sensory integration \& the psychophysics of flavour perception. In Food oral processing - Fundamentals of eating and sensory perception. Edited by Chen J, Engelen L. Oxford: Blackwell Publishing; 2012:203-219.

56. Steiner JE: Innate, discriminative human facial expressions to taste and smell stimulation. Annals NY Acad Sci 1974, 237:229-233.

57. Bozzi P, Flores D'Arcais G: Ricerca sperimentale sui rapporti intermodali fra qualità espressive [Experimental research on the intermodal relationships between expressive qualities]. Arch Psicol Neurol Psichiatr 1967, 28:377-420.

58. O'Boyle MW, Tarte RD: Implications for phonetic symbolism: the relationship between pure tones and geometric figures. J Psycholinguist Res 1980, 9:535-544.

59. Hevner K: Experimental studies of the affective value of colors and lines. J Appl Psychol 1935, 19:385-398.

60. Poffenberger AT, Barrows BE: The feeling value of lines. J App/ Psychol 1924, 8:187-205

61. Crisinel A-S, Spence C: The impact of pleasantness ratings on crossmoda associations between food samples and musical notes. Food Qual Prefer 2011, 24:136-140.

62. Deroy O: Tastes and shapes: Synaesthesia or metaphor: CenSes, University of London; Presentation given at The Nature of Taste, between Science and Aesthetics meeting; December 32009.

63. Marks LE: Metaphor and the unity of the senses. In Sensory science theory and applications in foods. Edited by Lawless HT, Klein BP, Lawless HT, Klein BP. New York: Marcel Dekker; 1991:185-205.

64. Marks LE, Hammeal RJ, Bornstein MH: Perceiving similarity and comprehending metaphor. Monogr Soc Res Child 1987, 52:1-102.

65. Liu CH, Kennedy JM: Form symbolism, analogy, and metaphor. Psychon B Rev 1997, 4:546-551.

66. Maurer D, Pathman T, Mondloch CJ: The shape of boubas: sound-shape correspondences in toddlers and adults. Dev Sci 2006, 9:316-322.

67. Seo H-S, Arshamian A, Schemmer K, Scheer I, Sander T, Ritter G, Hummel T: Cross-modal integration between odors and abstract symbols. Neurosci Lett 2010, 478:175-178

68. Hanson-Vaux G, Crisinel AS, Spence C: Smelling shapes: Crossmodal correspondences between odors and shapes. Chem Senses,

69. Bien N, ten Oever S, Goebel R, Sack AT: The sound of size: Crossmodal binding in pitch-size synesthesia: A combined TMS, EEG, and psychophysics study. Neurolmage 2012, 59:663-672.

70. Kovic V, Plunkett K, Westermann G: The shape of words in the brain. Cognition 2009, 114:19-28.

71. Bar M, Neta M: Visual elements of subjective preference modulate amygdala activation. Neuropsychologia 2007, 45:2191-2200.

72. Woods AT, Lloyd DM, Kuenzel J, Poliakoff E, Dijksterhuis GB, Thomas A: Expected taste intensity affects response to sweet drinks in primary taste cortex. Neuroreport 2011, 22:365-369.

73. Henrich J, Heine SJ, Norenzayan A: The weirdest people in the world? Behav Brain Sci 2010, 33:61-135.

74. Tozer J: The great HP Sauce revolt: online fury over salt cut that 'ruins the taste. [http://www.dailymail.co.uk/news/article-2036349/HP-Saucerevolt-Online-fury-salt-cut-ruins-taste.html]. 
75. Parise $\mathrm{CV}$, Spence $\mathrm{C}$ : Assessing the associations between brand packaging and brand attributes using an indirect performance measure. Food Qual Prefer 2012, 24:17-23.

76. Westerman SJ, Gardner PH, Sutherland EJ, White T, Jordan K, Watts D, Wells S: Product design: Preference for angular versus rounded design elements. Psychol Market 2012, 29:595-605.

77. Westerman SJ, Sutherland EJ, Gardner PH, Baig N, Critchley C, Hickey S, et al: The design of consumer packaging: Effects of manipulations of shape, orientation, and alignment of graphical forms on consumers' assessments. Food Qual Pref 2013, 27:8-17.

78. Stutts CA, Torres A: Taste interacts with sound symbolism. North Amer J Psychol 2012, 14:1. Downloaded from http://www.freepatentsonline.com/ article/North-American-Journal-Psychology/281111805.html.

doi:10.1186/2044-7248-1-12

Cite this article as: Spence and Ngo: Assessing the shape symbolism of the taste, flavour, and texture of foods and beverages. Flavour 2012 1:12.

\section{Submit your next manuscript to BioMed Central and take full advantage of:}

- Convenient online submission

- Thorough peer review

- No space constraints or color figure charges

- Immediate publication on acceptance

- Inclusion in PubMed, CAS, Scopus and Google Scholar

- Research which is freely available for redistribution 